\title{
دراسة جمالية في رسومات قصير عمره
}

Aesthetic study in the paintings of Amra Palace

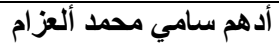

مدرس / كليه اريد الجامعية ـ قسم العلوم التطبيقية -

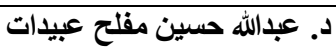

جامعه البلقاء التطبيقية

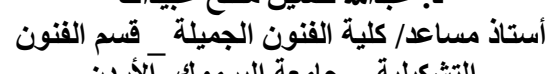

\section{Abstract}

التثكيلية__ جامعة اليرموك- الأردن الفين

The research, in this study investigated a sample of wall paintings of Amra palace which were executed on the palace walls and see lings in "Fresco" manner, so the research followed the analytical descriptive method that aims at revealing the beauties of these paintings represented in structure elements for the art work, the writing form and space, shadows and lights, and the color.

Also this research showed a brief look for the palace civilization reality its history its origin and its architecture description, then it showed asset of paintings with their description and analysis, based on the elements of art structure, and then showing the most important aesthetic and constructivism's for them also at the and of the research, the research concluded the most important finding and recommendations.

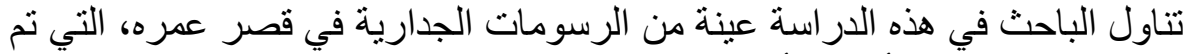

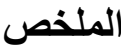

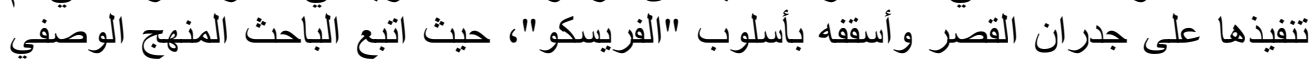

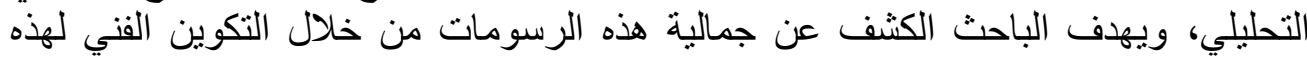

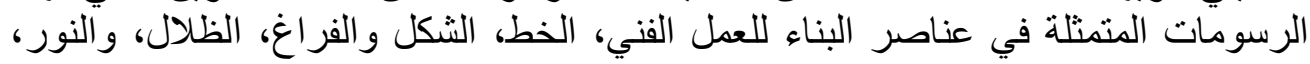

كما تم في هذه الدراسة عرض موجز لو اقع القصر الحضاري ناريخه، ونشأته،

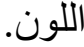

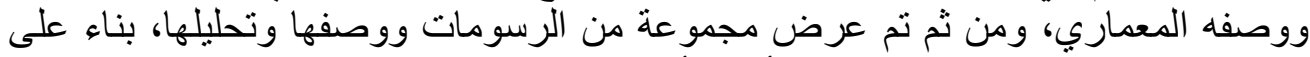

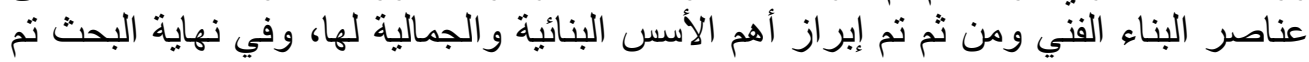

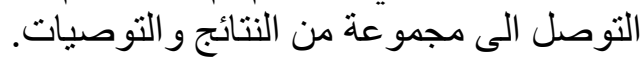

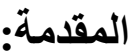

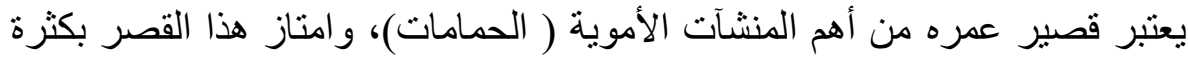

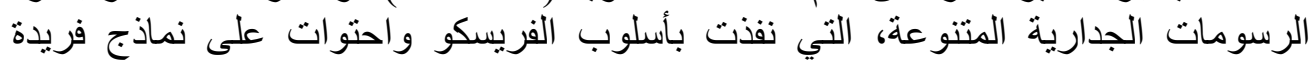

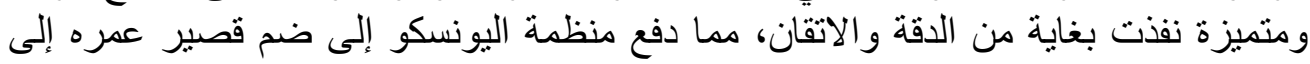


قائمة التراث العالمي، بسبب المواضيع التي تناولتها الرسومات الجدارية، التي توصف الحياة

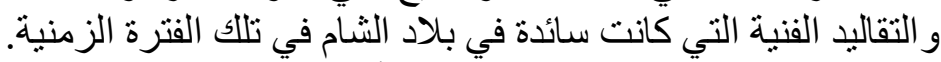

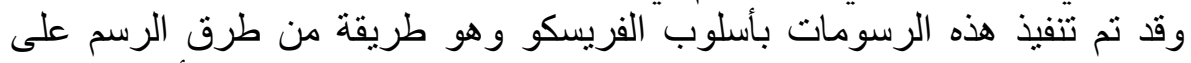

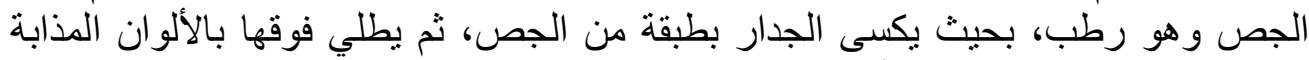

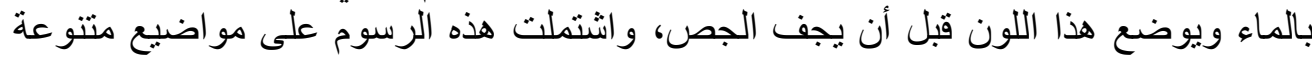

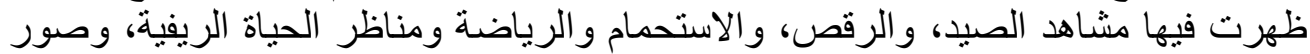
لنساء.

وتعد هذه الرسومات من أقدم الصور المائية الإسلامية، والتي تعد مصدراً غنياً

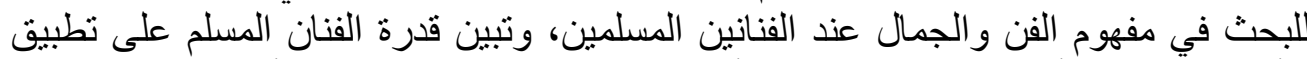

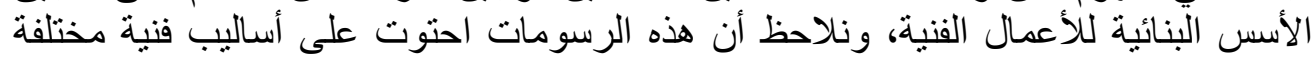

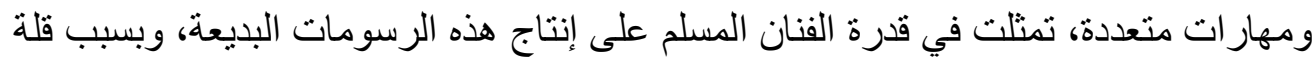

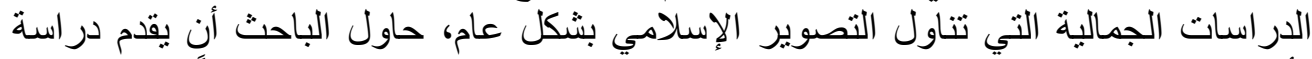

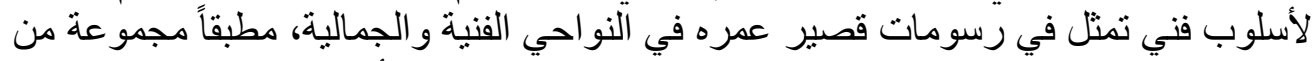

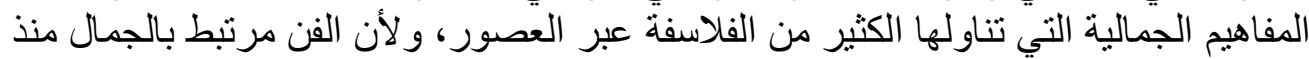

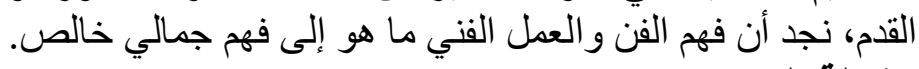

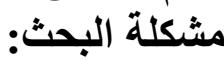

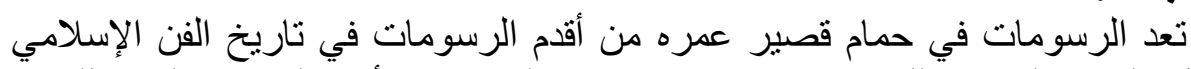

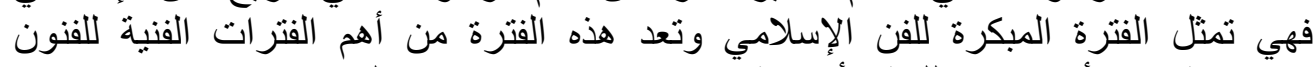

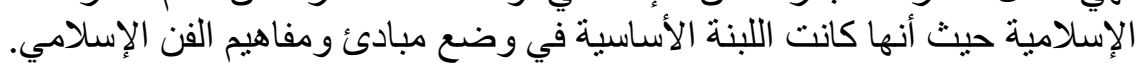

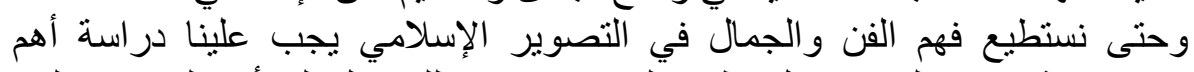

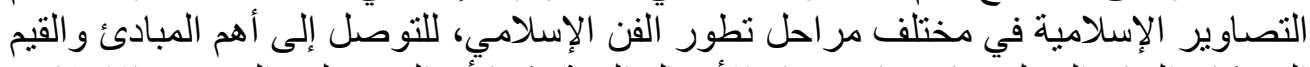

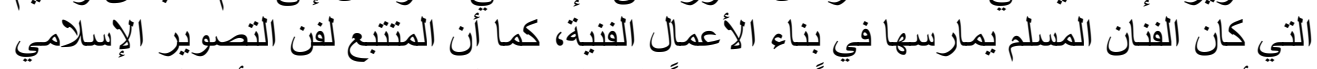

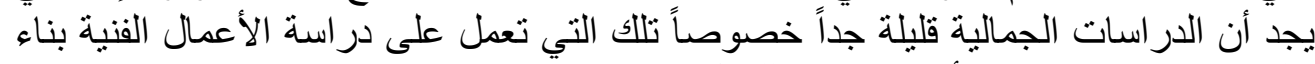
على العناصر الثكلية والأسس البنائية للعمل الفني.

يهدف البحث إلى التعرف على عناصر العمل الفني وأسس بناهه جماليا، في هدف البحث: إن رسومات قصير عمره.

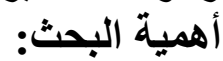

تنطلق أهمية البحث من استنمار عناصر العمل الفني وأسسه البنائية الجمالية في

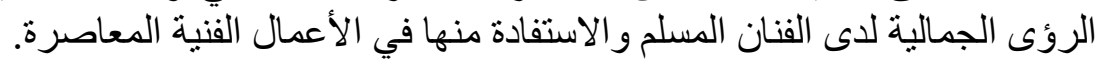

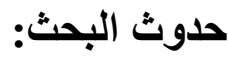
• الحد الزمني: النصف الأول الأول من القرن الثاني الهجري. ـ الحد المكاني: البادية الأردنية، ويبعد 65 كم إلى الثئية الثرق من عمان عاصمة المملكة الأردنية الهاشمية. • الحد الموضوعي: خمسة رسومات نفذت على جدران قصير عمره من الداخل.

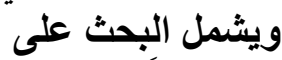

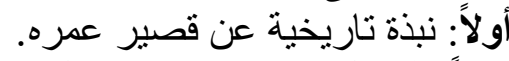

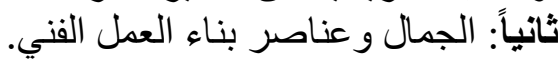




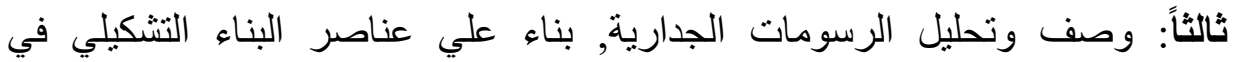

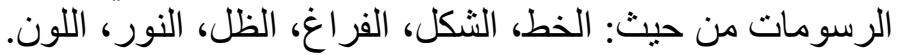

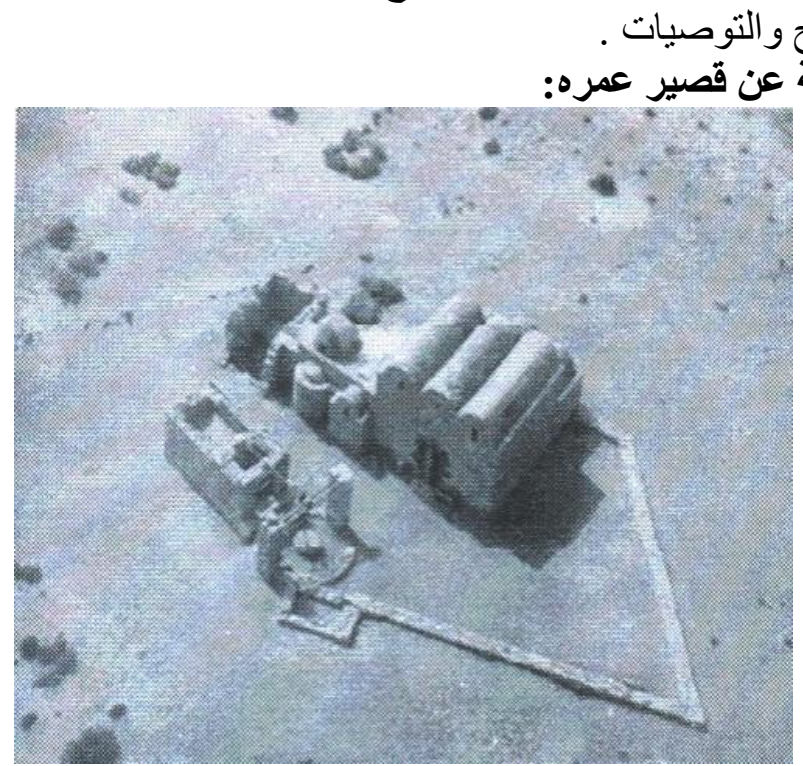

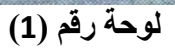

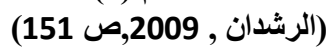

الموقع: يقع قصير عمره في البادية الأردنية ويبعد حوالي 65 كم إلى الثرق من الترن عمان، وقد

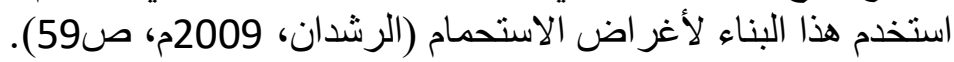
تخطيط القصير و أقسامه المعمارية:

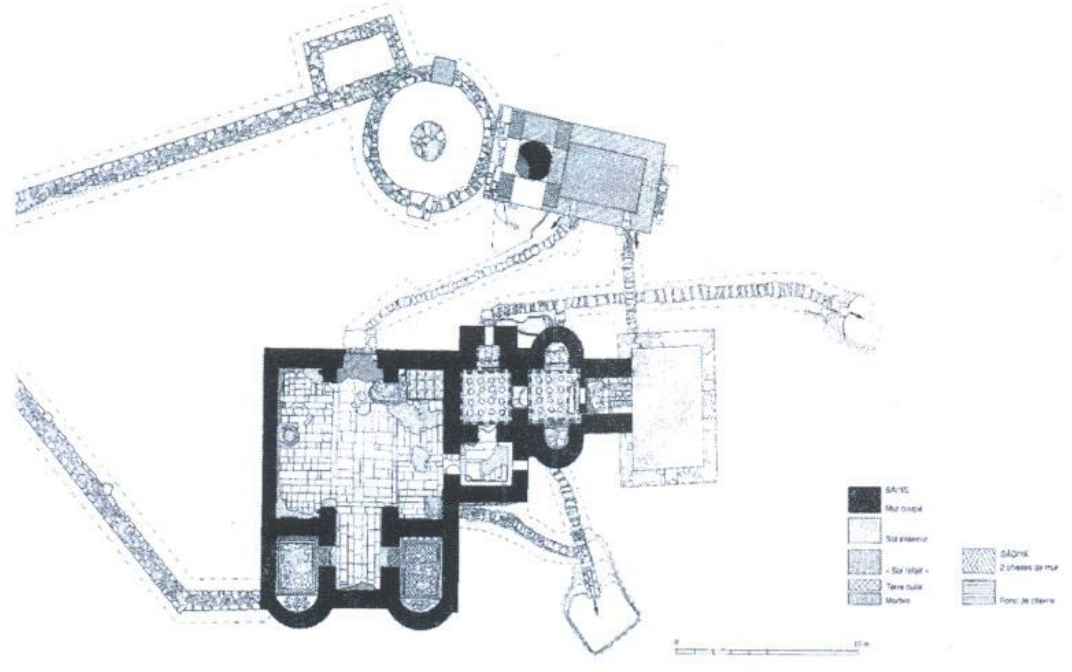

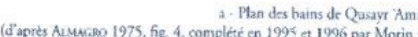

لوحة رقم (2)

(Vibert-Guigue: Bisheh,2007,pl.3) 
يعد قصير عمره من أصغر القصور الأموية التي شيدت في منطقة بلاد الثام ويتكون من ثلاث أقسام رئيسة:

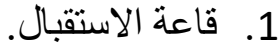

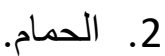

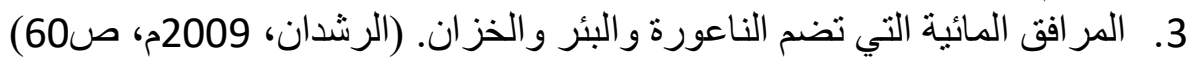

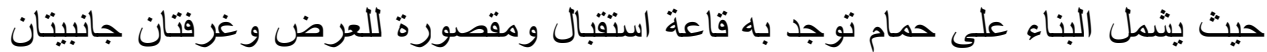

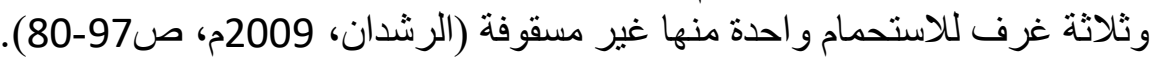

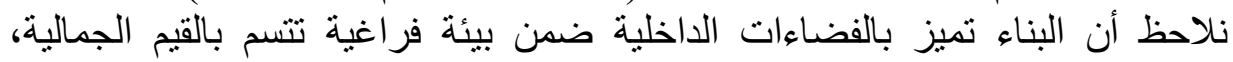

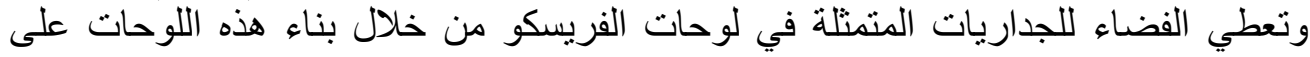

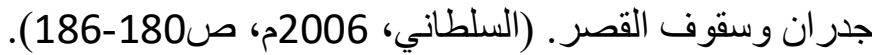

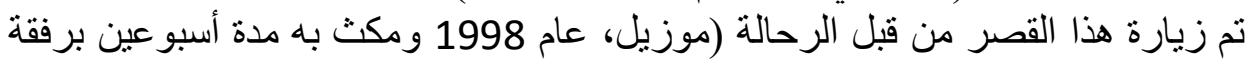

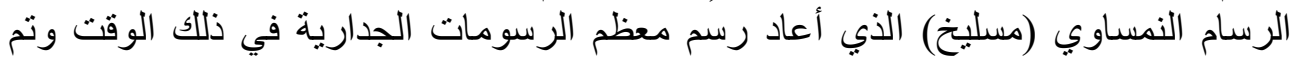

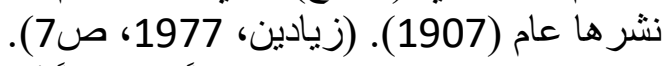

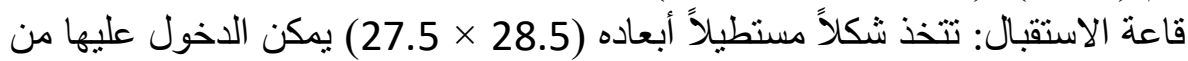

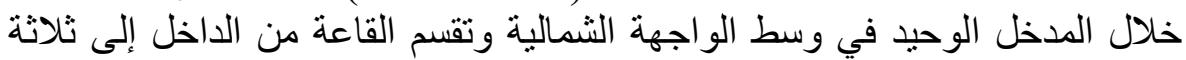

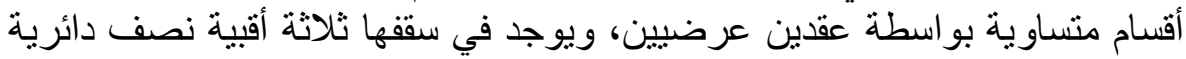

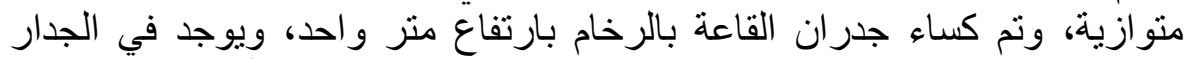

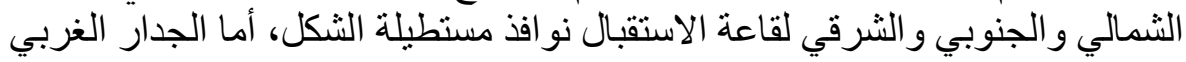

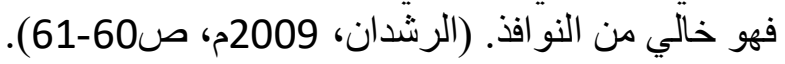

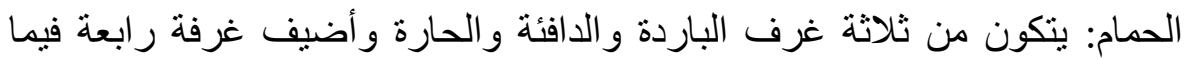

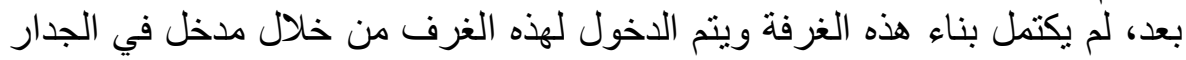

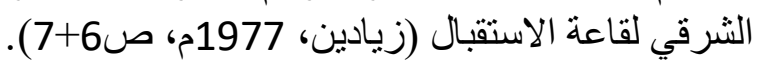

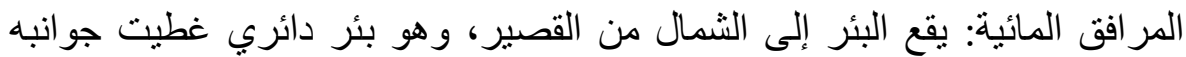

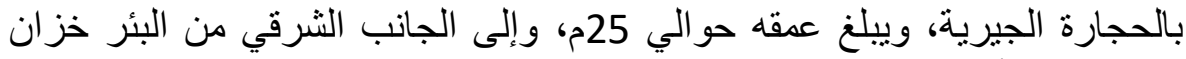

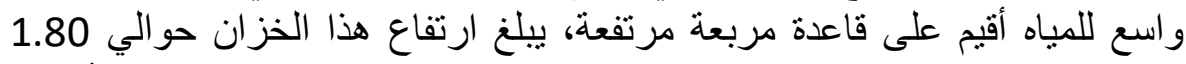

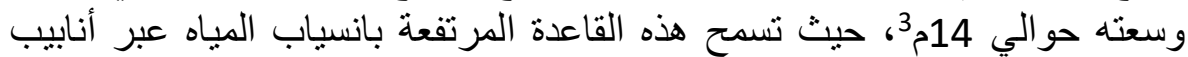

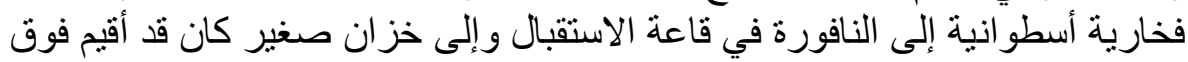

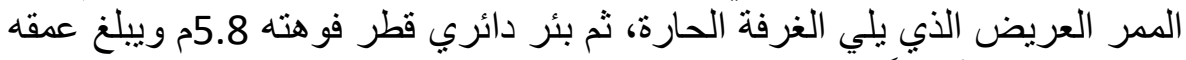

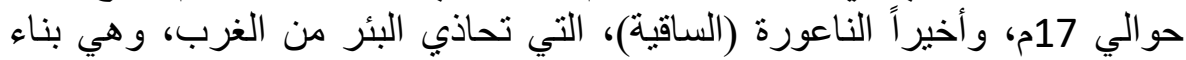

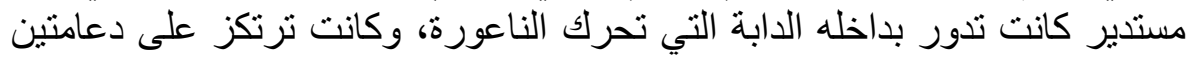

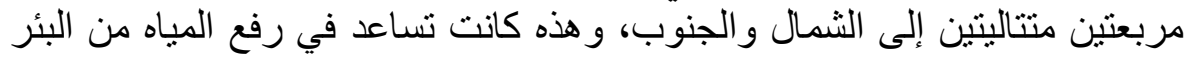

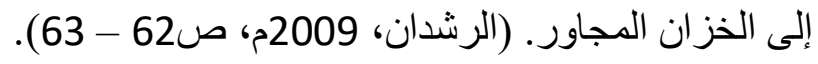

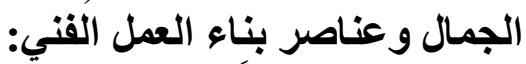

الجمال فنياً : هو وحدة ألعلاقات الثكلية بين الأشياء التي تدركها الحواس, (أبو

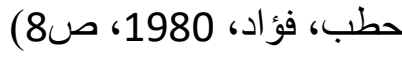




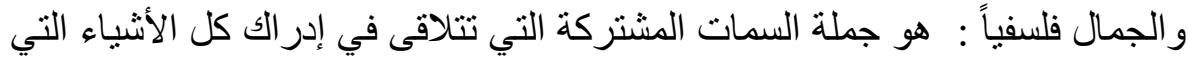

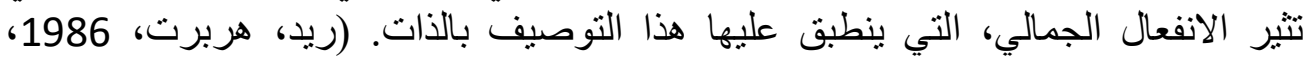

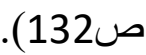

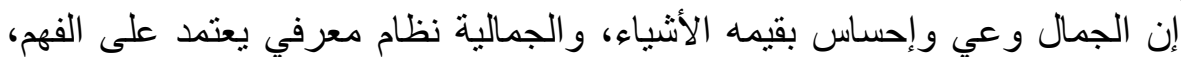

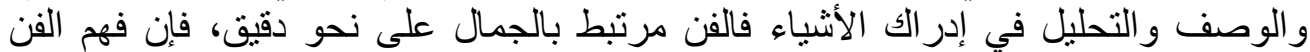

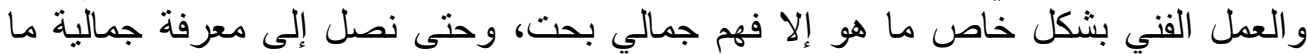

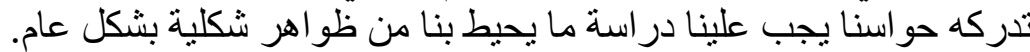

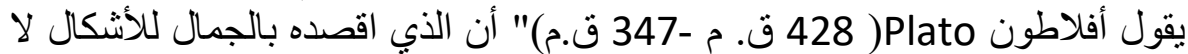

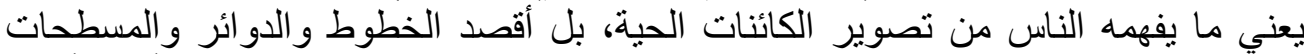
و الحجوم المكونة منها بو اسطة الأدوات، وأؤكد بأن هذه الأشكال ليست جميلة جمالاً نسبياً مثل

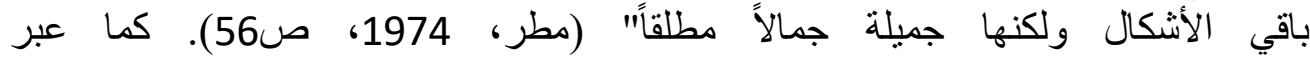

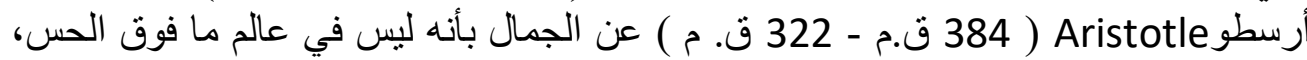

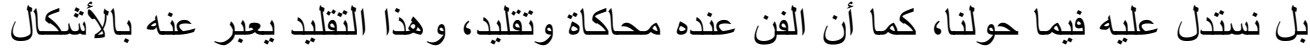

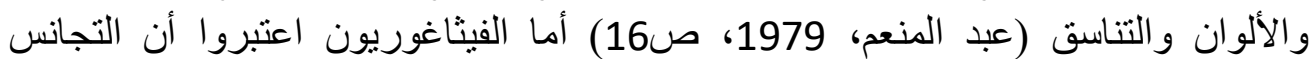

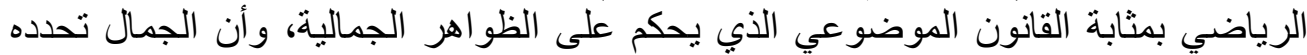
النسب والتو افقات الرياضية الصحيحة التي تحكم وتتخلل بنية العمل الجميل ومظهره (أبو التيون

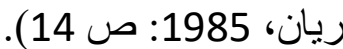

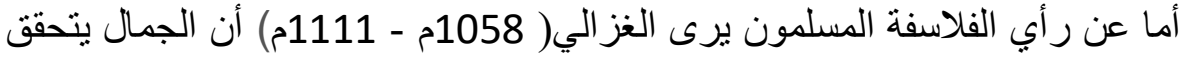

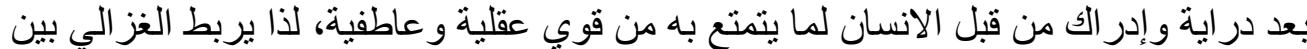

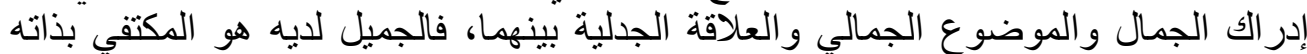

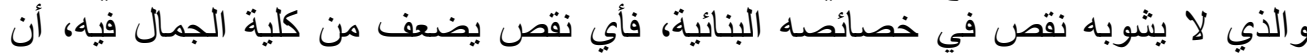
الجميل المحتكم إلى التناسق العام والتوازن القائم بين أجزاءه وكمال التكوين الفني كله.

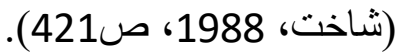

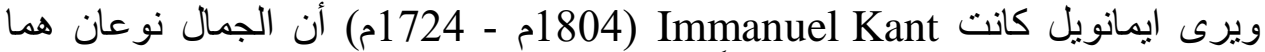

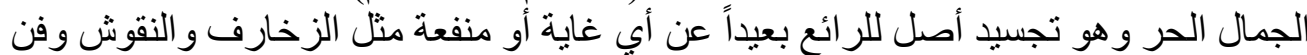

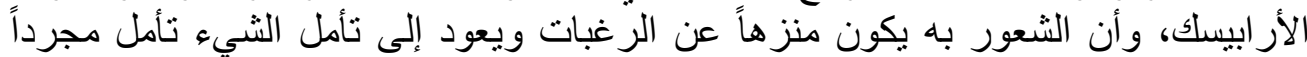

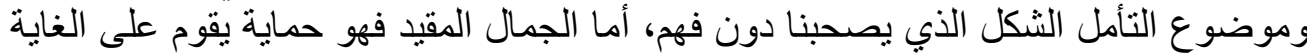

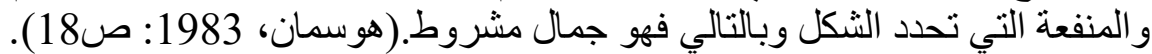

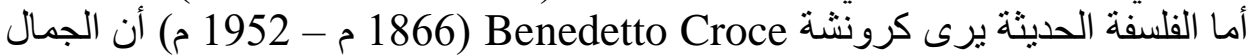

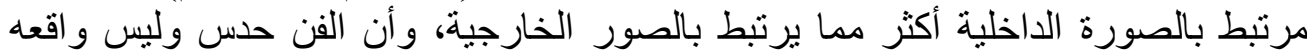

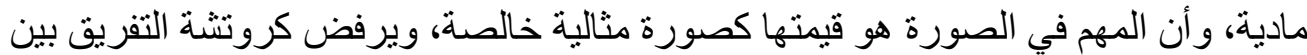

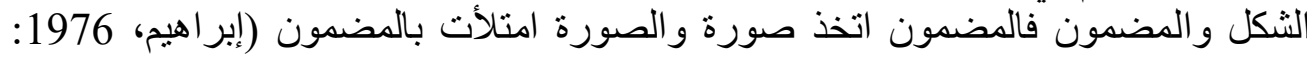

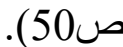

نلاحظ أن هنالك صعوبة في تحديد المعايير الجمالية، فهي نظل نسبية في الغالب

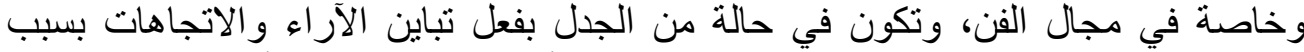

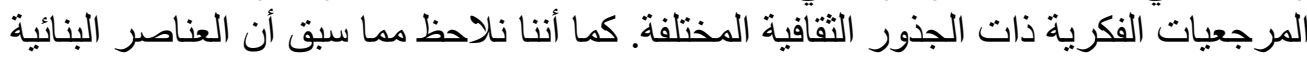

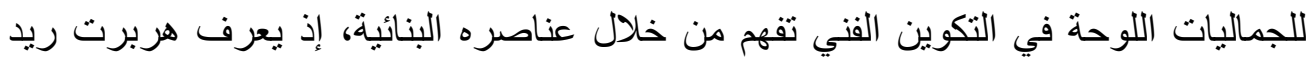


Herbert Read

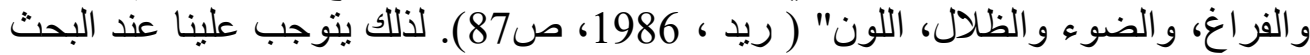

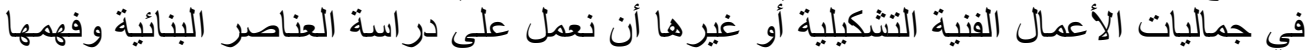

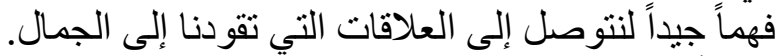

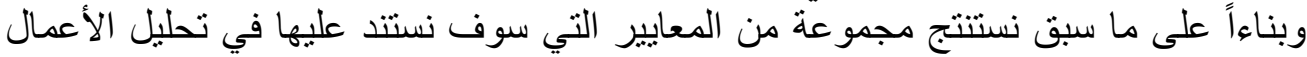
الفنية لاستخلاص القيم الجمالية لها:

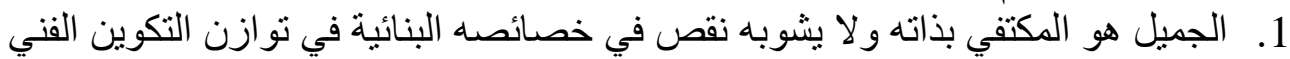
2. كلرى كانت أن الجمال الحر بعيد عن أي غاية أو منفعة مثل الزخارف و النقوش. وللوصول إلى القيم الجمالية للأعمال الفنية، يجب أن نتحقق من البناء الفني وذلك من

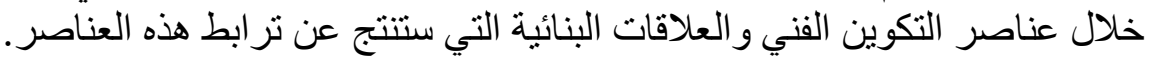

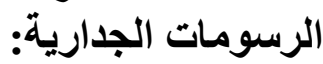
سوف يتم اختيار مجموعة متتوعة من الرسومات التي تم تتفيذها على جدران

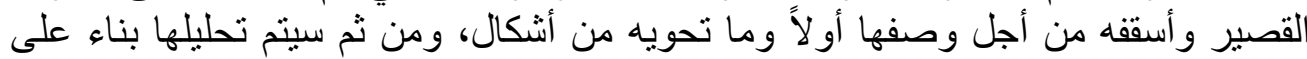

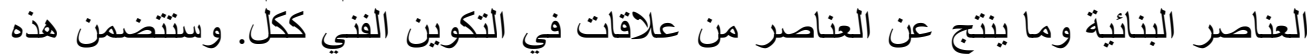
المجمو عة خمسة لوحات فنية سيتة سيتم تناو لها مفردة.

وصف وتحليل الأعمال افنية:

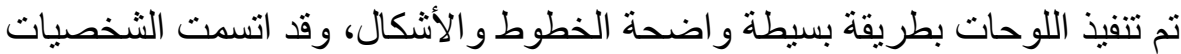

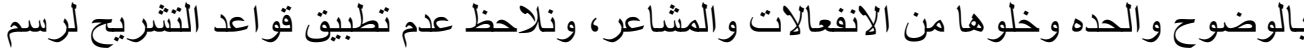

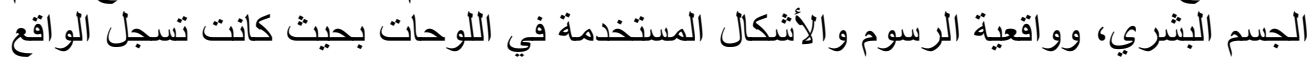

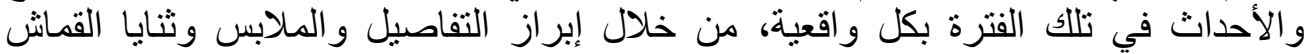

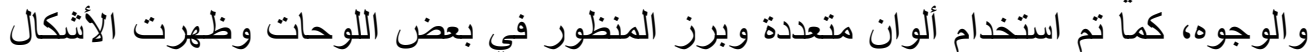

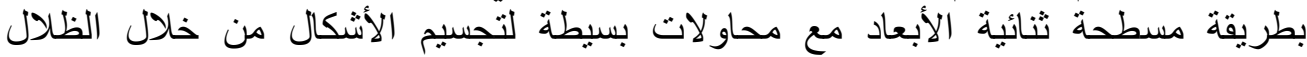
و واستخدام درجات لونية متعددة.

\section{وصف اللوحة رقم (3):}

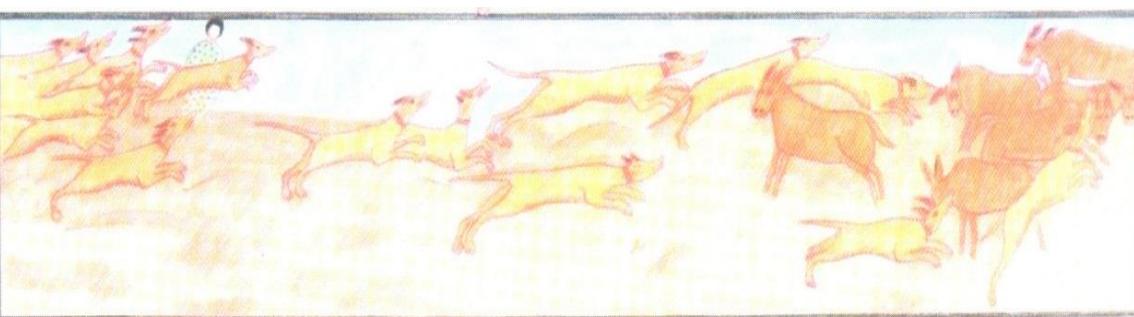

=

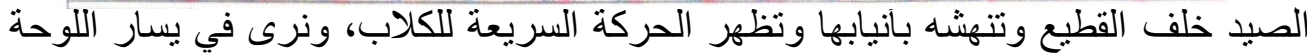

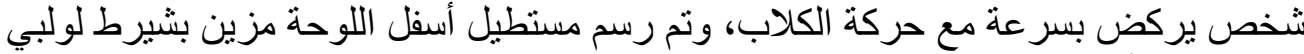
الثكل وبين أجز ائه دو ائر صغيرة متركة متعددة. التحليل الفني اللوحة رقم (3): 


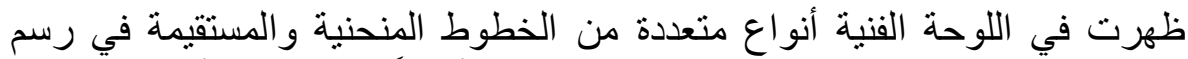

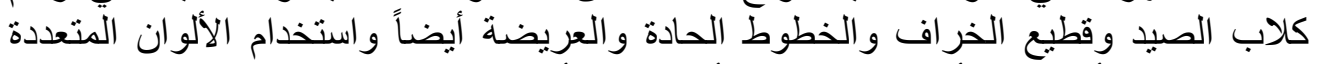

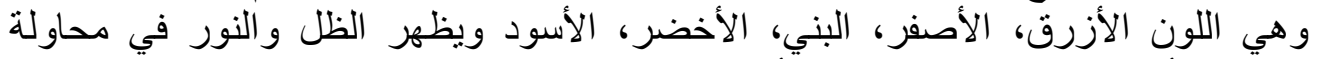

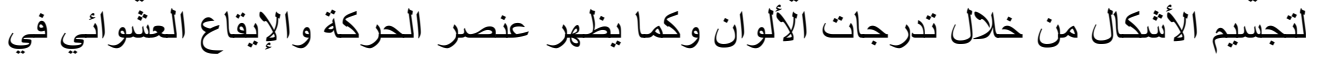

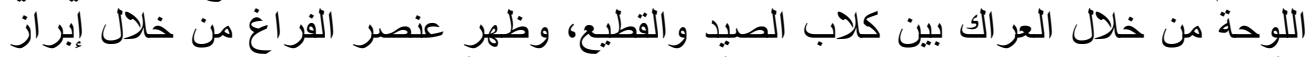

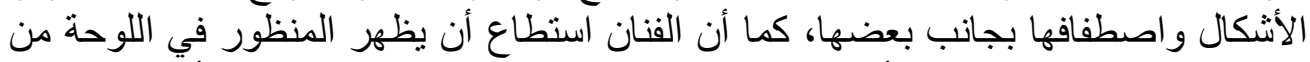

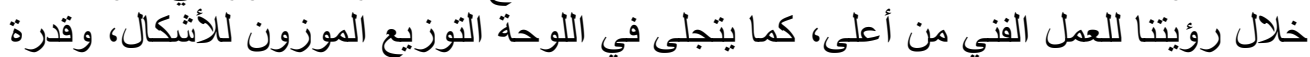

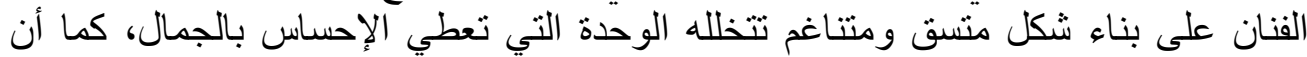

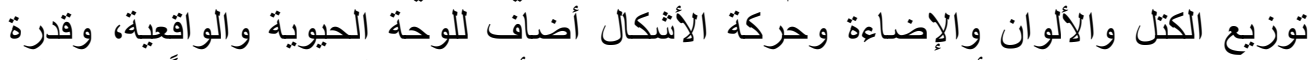

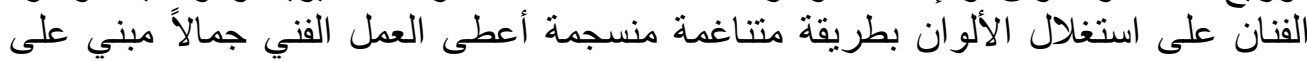
عناصر العمل الفني وما ينتج عنها من علاقات الفات وصف اللوحة رقم (4):

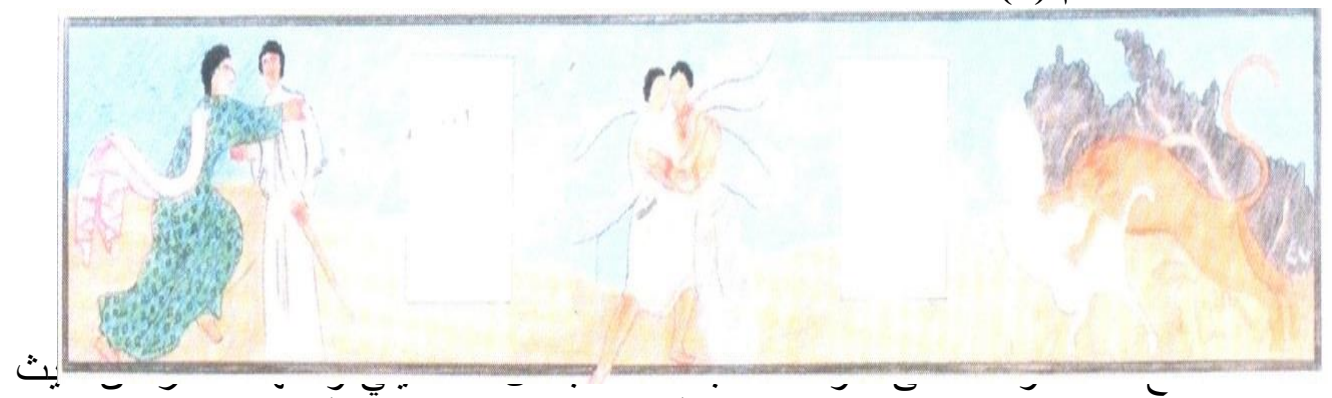

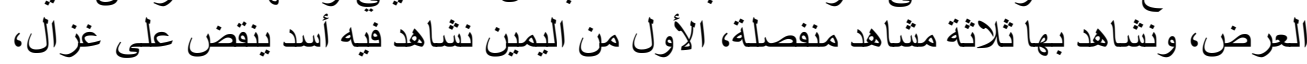

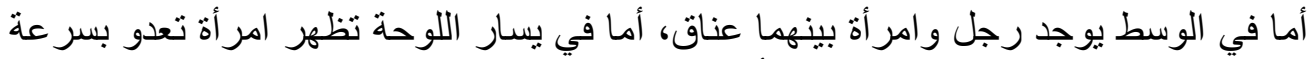

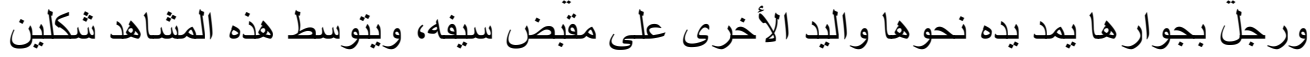

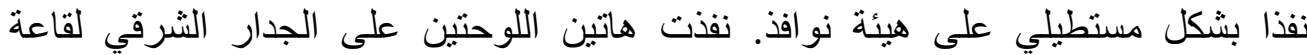

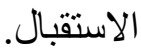

\section{التحليل القني اللوحة رقم (4):}

تم تقسيم اللوحة إلى ثلاثة أقسام متساوية يفصل بينهما نو افذ بشكل مستطيل، كلا

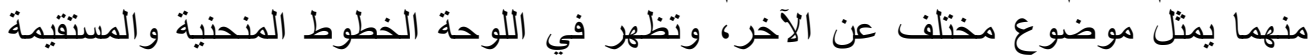

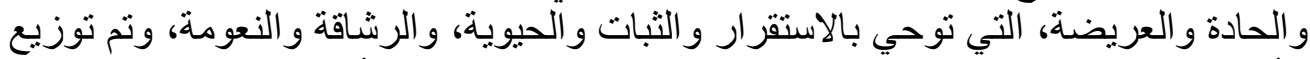

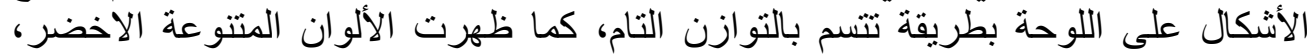

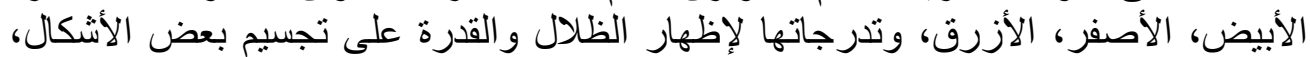

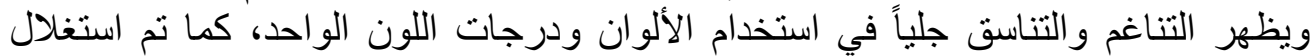

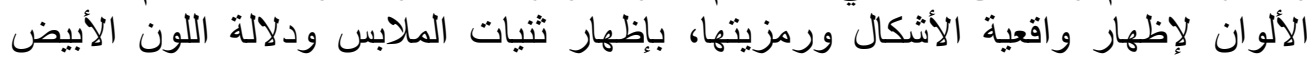

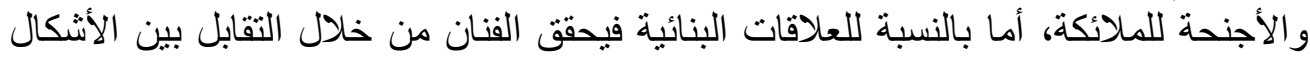

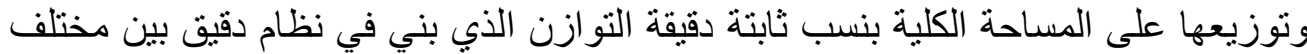

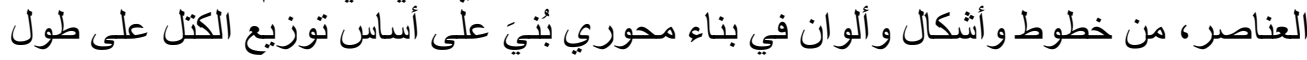

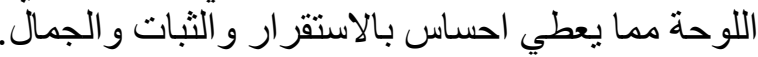

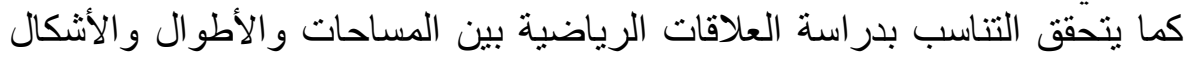
والفراغات التي تم توزيعها على طول اللوحة بإيقاع ذا مسافات متساوية ولكن بأنثكال 
مختلفة،يتوسطها مستطيلين متشابهين يقسمان اللوحة إلى ثلاثة أقسام مما أضفى الحيوية

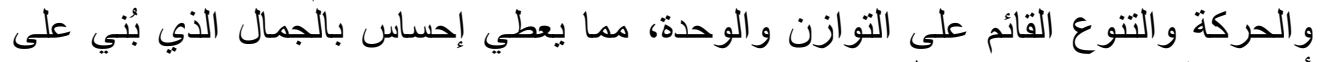
أسس فنية في بناء فني متكامل.

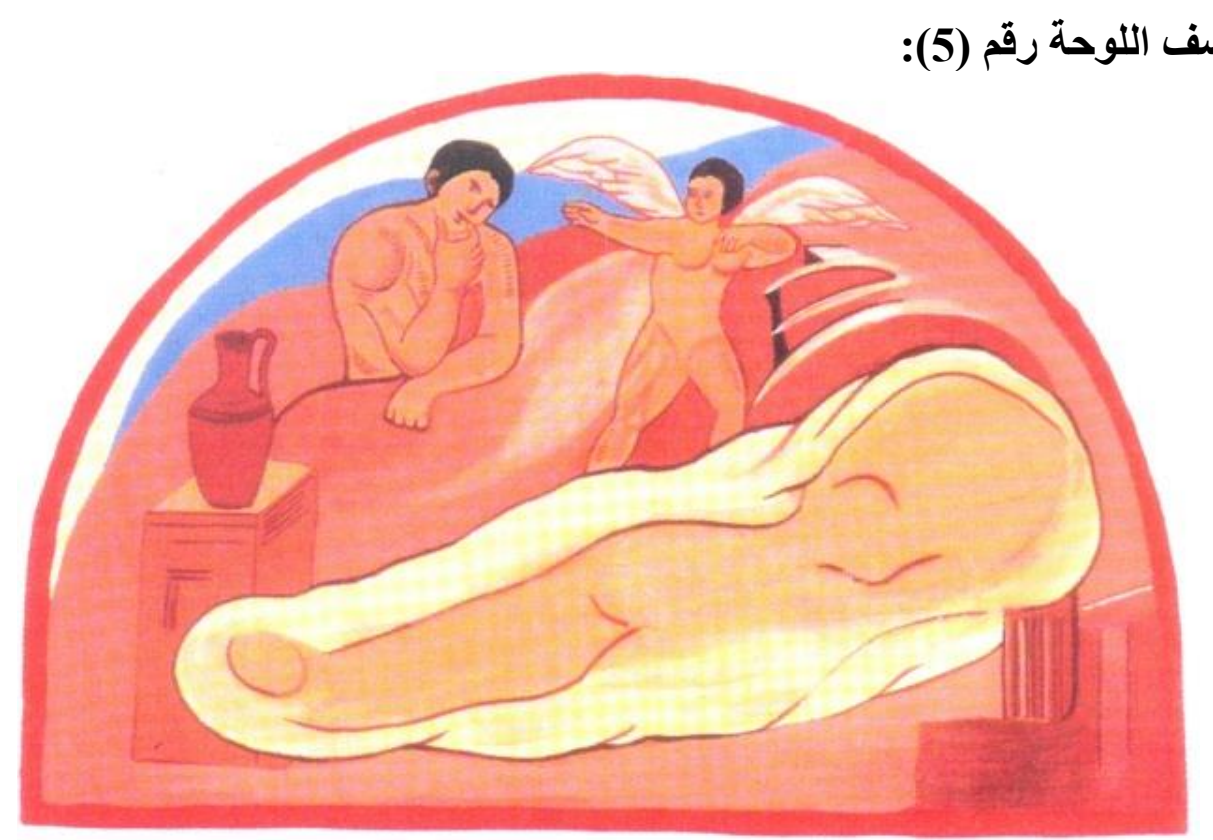

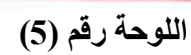

(Vibert-Guigue: Bisheh,2007,pl.133)

نفذت اللوحة بشكل نصف دائري، يظهر في أعلى اللوحة إلى اليمين رسم لطفل له له

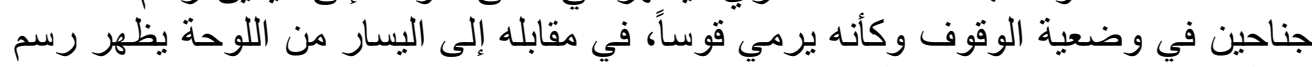

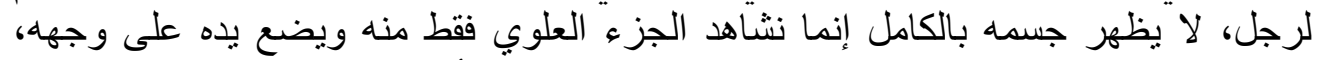

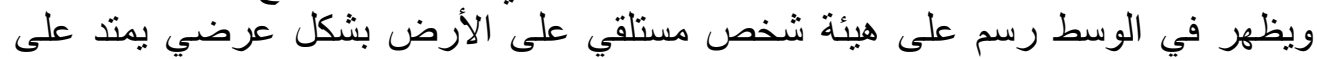

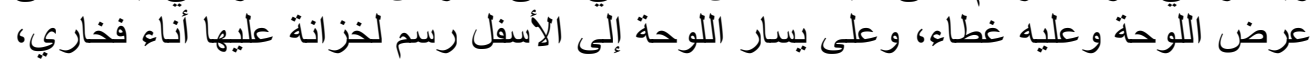

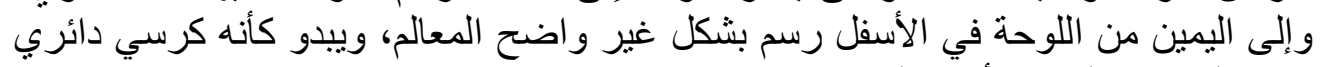

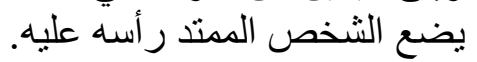
التحليل الفني اللوحة رقم (5):

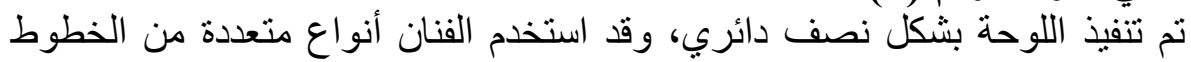

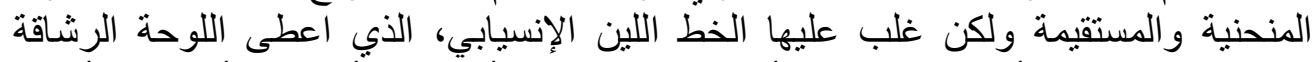

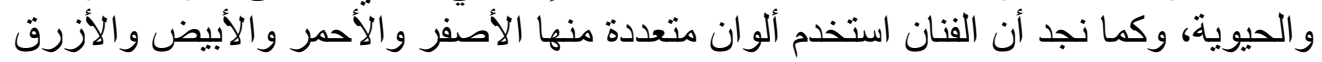


و الأسود ودرجات هذه الألوان لإظهار البعد الثالث و إظهار العمق مما أعطى اللوحة الإنسجام

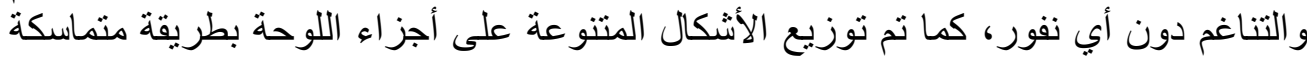

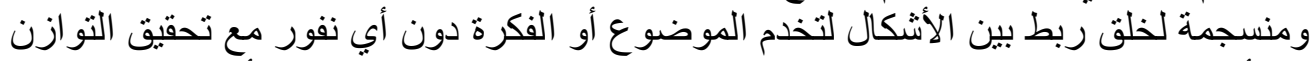

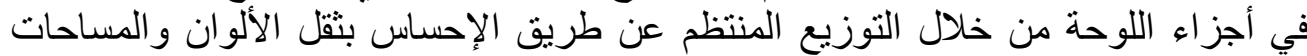

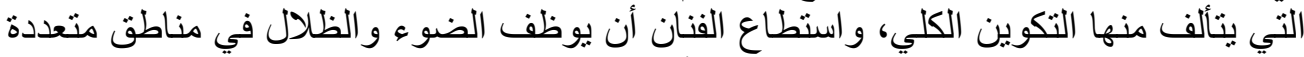

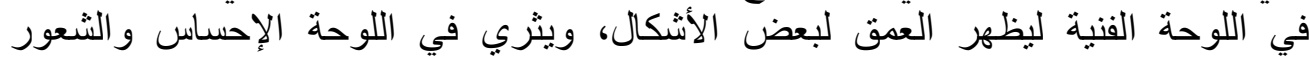

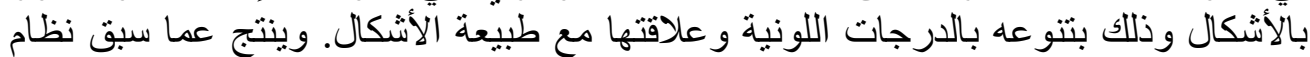
رتب على صورة تتر ابط أجز ائه على شكل متسق يتسم بالوحدة ولات الأنسجام وفق الأسس البنائية اللعمل الفني الذي يتسم بالجمال.

وصف اللوحة رقم (7) :

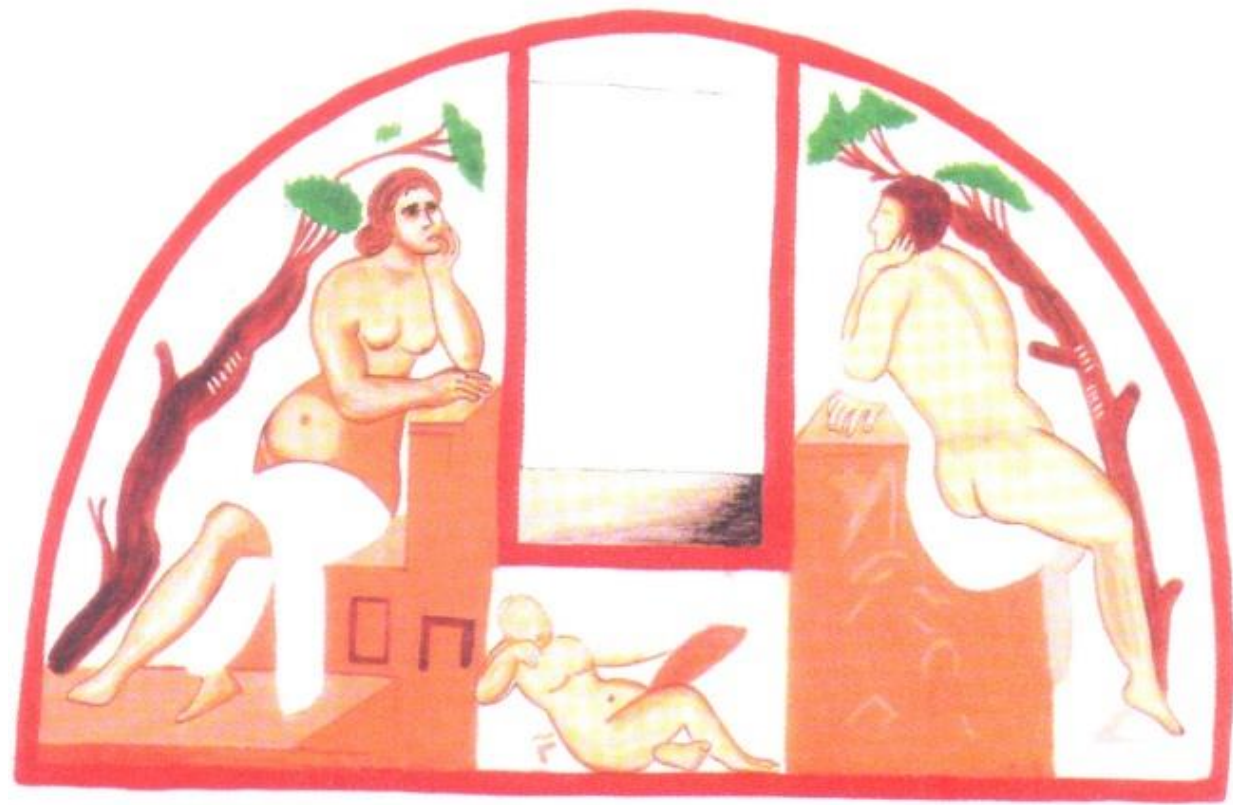

(6) اللوحة رقم

(Vibert-Guigue: Bisheh,2007,pl.133)

نفذت هذه اللوحة بشكل نصف دائري كاللوحة السابقة، لكن يتو سط اللوحة نافذة بشكل

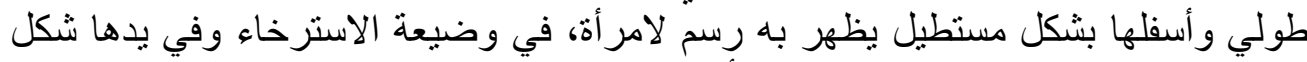

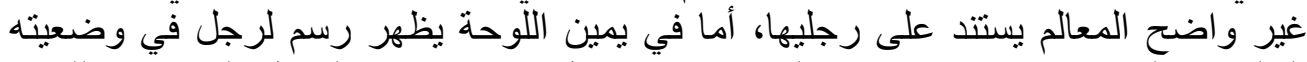

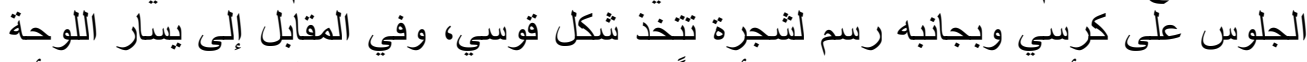

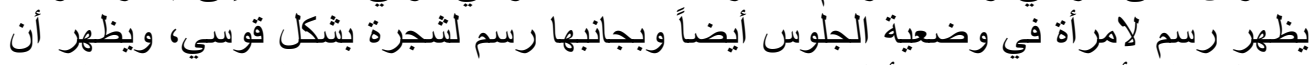

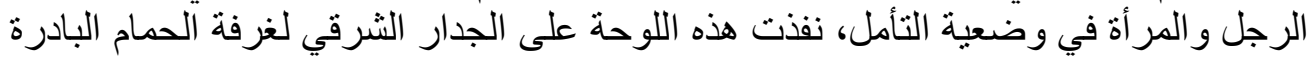

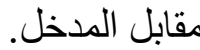

$$
\text { التحليل القني اللوحة رقم (6): }
$$

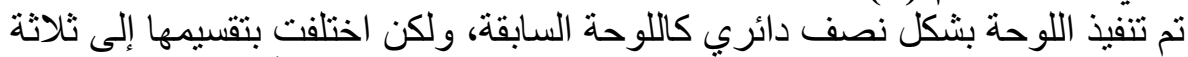

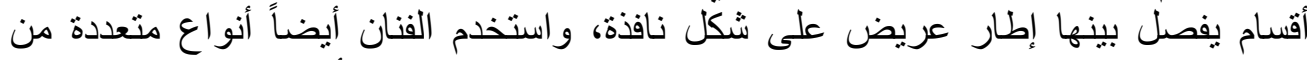

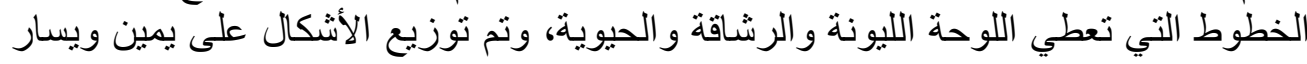


اللوحة محققاً نو ازن محوري يكاد يكون أشبه بالتماتل من بعض الاختافلافات البسيطة، وظهر

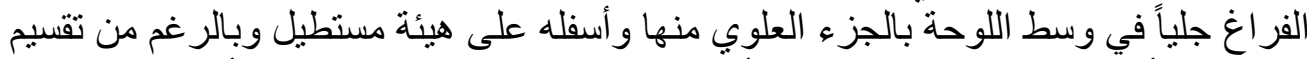

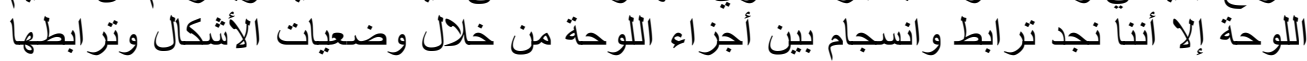

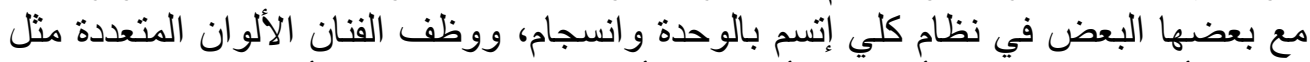

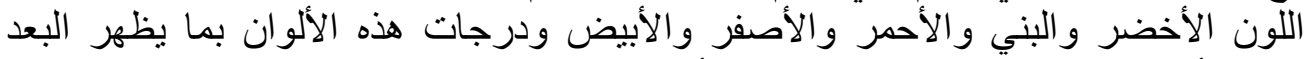

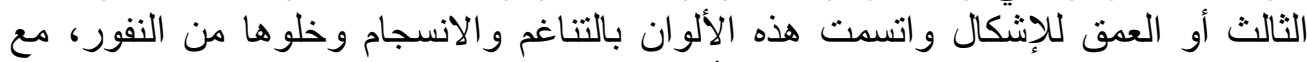

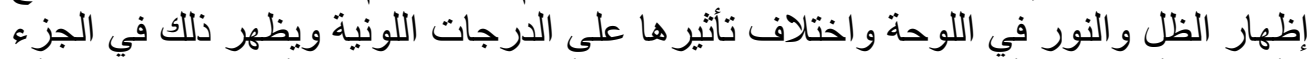

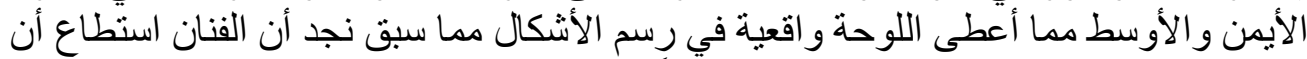

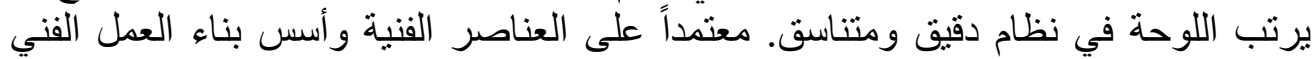
لتتسم هذه اللوحةٌ بالجمال. 
وصف اللوحة رقم (7):

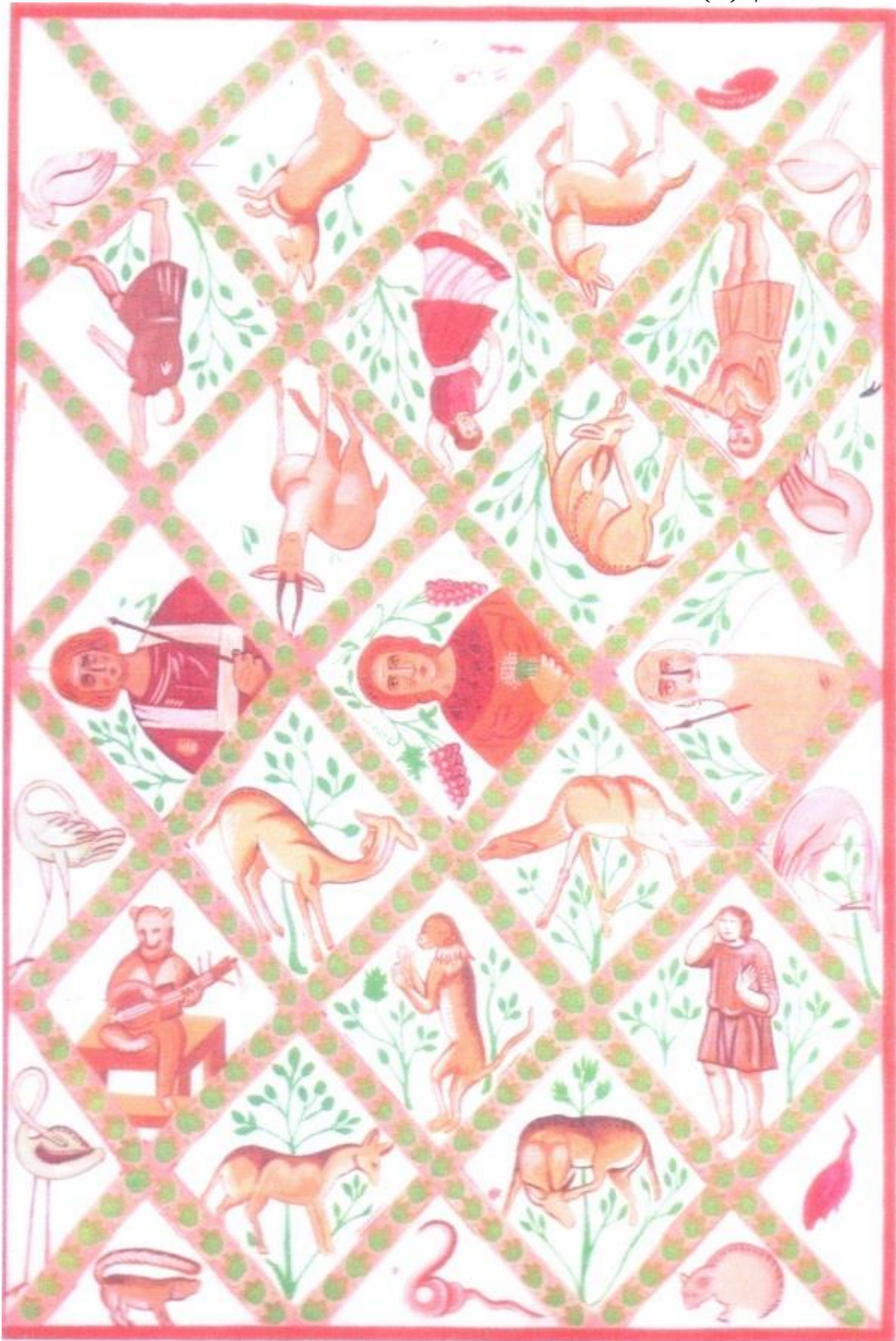

(7) اللوحة رقم

(Vibert-Guigue: Bisheh,2007,pl.134)

نفذت اللوحة بشكل مستطيل، حيث تم تقسيم اللوحة بأثرطة متقاطعة تزينها أوراق

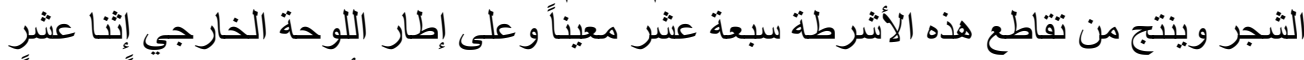

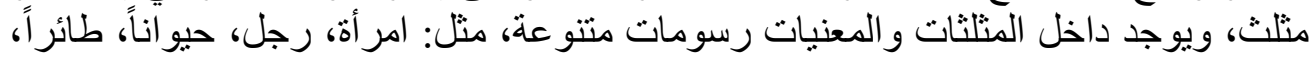

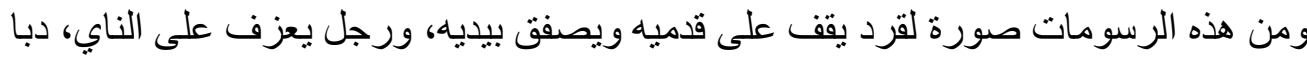


يجلس على مقعد ويعزف على العود، ورسم لر اقصة ورجل يصفق، وفي وسط اللوحة ثلاثة رسومات تمثل رجلاً بمختلف مر احل حياته، نفذت هذه اللوحة في القبة في سقف غرفة وفة الحمام

التحليل الفني اللوحة رقم (7):

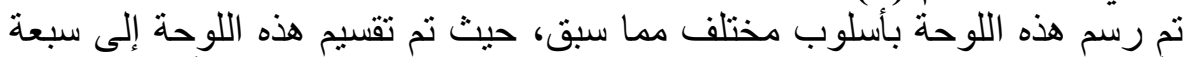

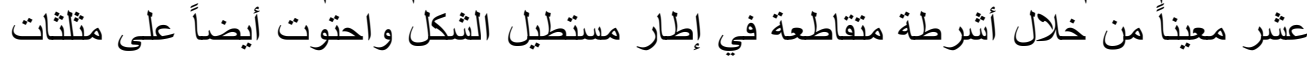

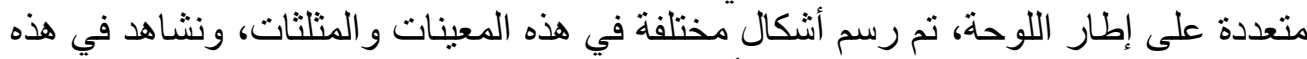

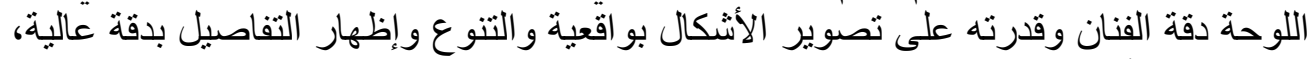

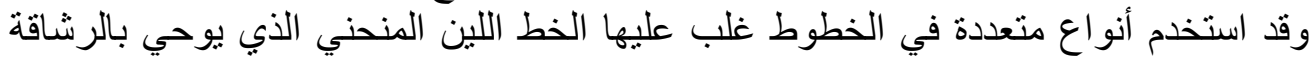

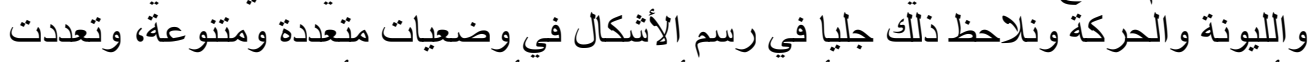

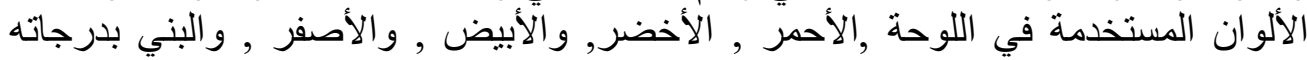

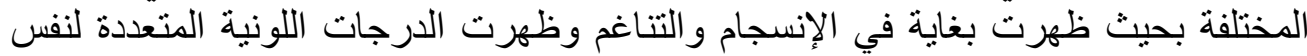

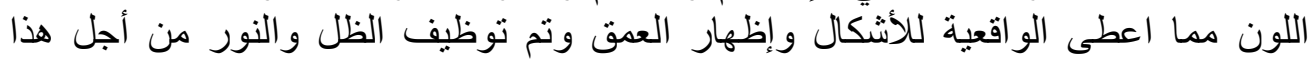

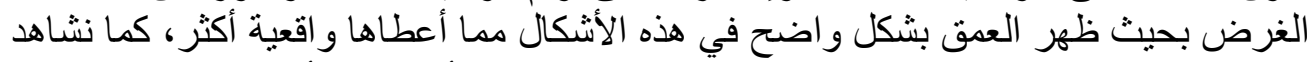

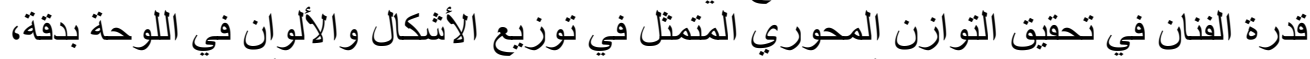

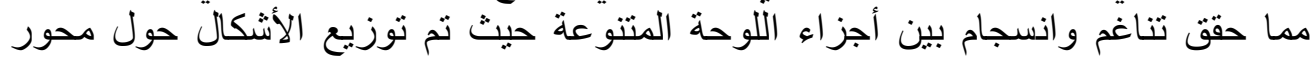

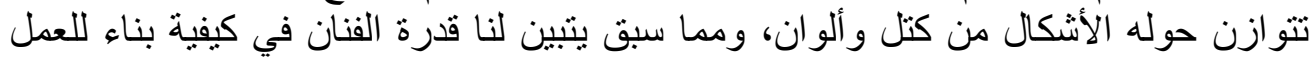

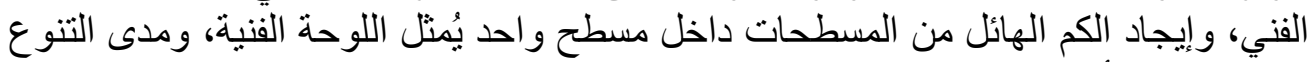

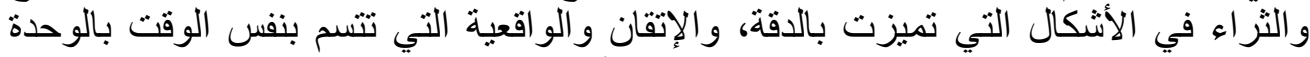
و الانسجام التام، مما يؤدي إلى بناء عمل فني على أسس فنية تتسم بالجمال التهال.

النتائج

يمكن تلخيص النتائج في مجمو عة من النقاط المهرة 1. قدرة الفنان الملم على توظيف العناصر الفنية المتمثل في الخط والثنكل و الفراغ الغ الفي

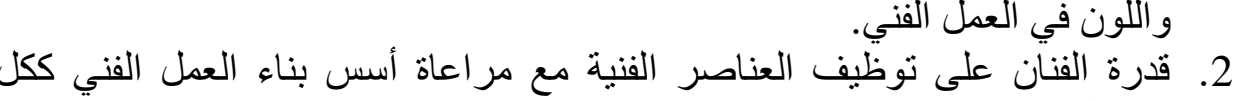
المنمثل في الوحدة التوازن الإنى الإنسجام، التناسب. 3. قدرة الفنان على إنتاج أعمال فنية وفق الإنس أسس البناء الفني التي تتسم بالجمال وفق الآر اء المتعددة التي تبحث في الجمال و الفن.

1. در اسة رسومات التراث الفني الإسلامي وفق الأسس العلمية للوصول إلى أسس بناء وتشكيل العمل الفني بهدف تحقيق التيق رؤية فنية جمالية.

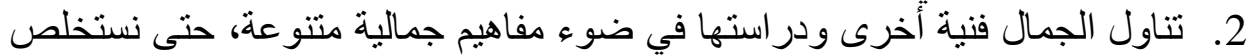
أسس جديدة ورؤية جمالية في بناء الثكل في التصوير فئر الإسلامي. 
3. التوصل الى در اسات مقارنة تدرس تطور مفهوم الجمال في الفترات الفنية الإسلامية

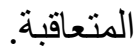

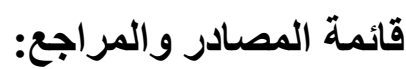

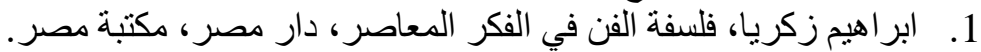

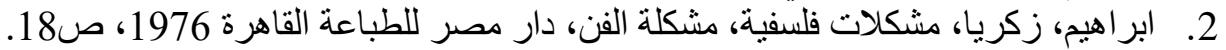

3. أبو ريان، محمد علي، تاريخ الفكر الفلسفي من طاليس الى افلاطون، دارئ دار المعرفة الجامعية في

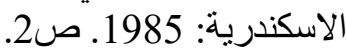

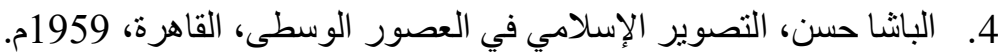

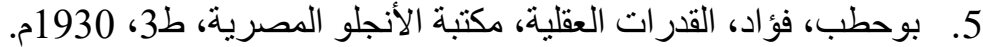

6. الرشدان، وائل منير، القصور الأموية في المملكة الأردنية الهانثمية، جامعة الملك سعود

2009م. (الرندان،

7. زيادين، فوزي، قصير عمره الأموي، دارة الآثار العامة، عمان، 1977م. الطمان.

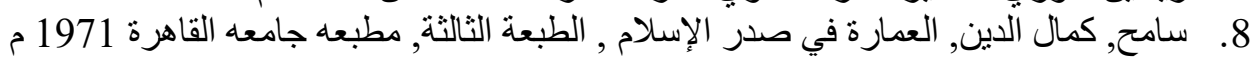

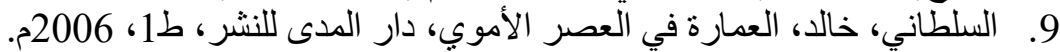

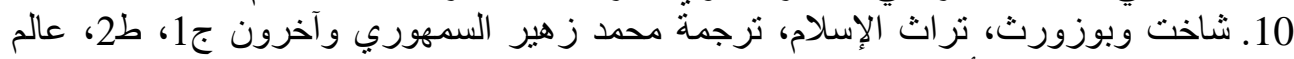

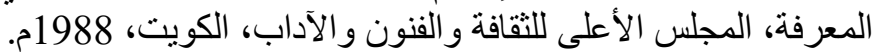

11. مطر، أميرة حلمي، فلسفة الجمال، ونشأتها وتطور ها، دار الثابلة الثقافة للنشر والتوزيع القاهرة ،

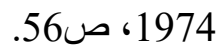

12. هربرت، زيد، معنى الفن، ترجمة سامي حسنية، مراجعة مصطفى حيب،، دار الكتاب العربي،

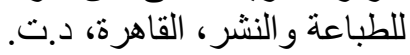

13. هوسمان، دني، علم الجمال، ص18، نرجمة ظافر الحسن، منشورات عويدات، بيروت 1983

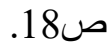

14. Vibert - Guigue, clande a Bisheh, Ghazi, Lepinturesde Qusayr

Amra, Un Bain Omeyyade La BadiyaJordanienne, 2007. 